\title{
ARTE E EDUCAÇÃO: O TEATRO COMO RECURSO METODOLÓGICO NO TRABALHO PEDAGÓGICO NA ALFABETIZAÇÃO
}

\author{
ARTE Y EDUCACIÓN: EL TEATRO COMO RECURSO METODOLÓGICO EN EL \\ TRABAJO PEDAGÓGICO EN LA ALFABETIZACIÓN
}

\author{
ART AND EDUCATION: THE THEATER AS A METHODOLOGICAL RESOURCE IN \\ PEDAGOGICAL WORK IN LITERACY
}

\author{
Marta Silene Ferreira BARROS ${ }^{1}$ \\ Jaqueline Delgado PASCHOAL ${ }^{2}$ \\ Ana Letícia FERREIRA ${ }^{3}$ \\ Priscila Cordeiro Soares BARROS ${ }^{4}$
}

RESUMO: O presente estudo objetiva-se discutir a importância do teatro e sua relação com a educação no sentido de considerar os benefícios que esta linguagem pode proporcionar para o trabalho pedagógico na sala de aula, pensado como um elemento metodológico na prática de letrar e alfabetizar, enfatizando sua contribuição ao processo alfabetizador visando o desenvolvimento integral da criança. Esta temática se insere na discussão atual sobre a especificidade das artes cênicas especialmente o teatro como recurso que necessita ser visto de forma sistemática, e, reconhecido como um campo científico com intencionalidade na formação da criança pequena no processo de alfabetização. A questão chave que envolve a análise é a seguinte: qual relação existe entre a arte e educação e como o teatro pode ser considerado como um subsídio relevante e intencional na prática do professor no processo de educação da criança na alfabetização? Trata-se de uma pesquisa qualitativa com fundamento na abordagem crítico dialética que propõe uma possibilidade metodológica diferenciada de ensino, para dinamizar a prática em sala de aula, pensando o teatro como recurso diferenciado na alfabetização e letramento, nos anos iniciais do Ensino Fundamental. Busca-se com esse estudo contribuir para que os profissionais das artes Cênicas e da Pedagogia, tenham um novo olhar para o Teatro na práxis pedagógica.

PALAVRAS-CHAVE: Educação. Artes cênicas. Teatro. Alfabetização. Letramento.

RESUMEN: El presente estudio se objetiva discutir la importancia del teatro y su relación con la educación en el sentido de considerar los beneficios que este lenguaje puede proporcionar para el trabajo pedagógico en el aula, pensado como un elemento metodológico en la práctica

\footnotetext{
${ }^{1}$ Universidade Estadual de Londrina (UEL), Londrina - PR - Brasil. Professora Associada do Departamento de Educação e do Programa de Pós-Graduação em Educação. ORCID: <https://orcid.org/0000-0002-1924-8490>. Email: mbarros_22@hotmail.com

${ }^{2}$ Universidade Estadual de Londrina (UEL), Londrina - PR - Brasil. Professora Associada do Departamento de Educação e do Programa de Pós-graduação em Educação. ORCID: <https://orcid.org/0000-0002-7961-2362>. Email: jaquelinedelgado@uol.com.br

${ }^{3}$ Universidade Estadual de Londrina (UEL), Londrina - PR - Brasil. Pós-graduanda em Educação. ORCID: <https://orcid.org/0000-0003-1321-6911>.E-mail: leticiavieira1995@hotmail.com

${ }^{4}$ Universidade Estadual de Londrina (UEL), Londrina - PR - Brasil. Pós-graduanda em Educação. ORCID: <https://orcid.org/0000-0003-4074-2714>. E-mail: pbarros18@gmail.com
} 
de letrar y alfabetizar, enfatizando su contribución al proceso alfabetizador para el desarrollo integral del niño. Esta temática se inserta en la discusión actual sobre la especificidad de las artes escénicas especialmente sentido el teatro como recurso que necesita ser visto de forma sistemática y reconocido como un campo científico con intencionalidad en la formación del niño pequeño en el proceso de alfabetización. La cuestión clave que implica el análisis es la siguiente: ¿Qué relación existe entre el arte y la educación y cómo el teatro puede ser considerado como un subsidio relevante e intencional en la práctica del profesor en el proceso de educación del niño en la alfabetización? Se trata de una investigación cualitativa basada en el enfoque crítico dialéctico que propone una posibilidad metodológica diferenciada de enseñanza, para dinamizar la práctica en el aula, pensando el teatro como recurso diferenciado en la alfabetización y letra, en los años iniciales de la Enseñanza Fundamental. Se busca con ese estudio contribuir para que los profesionales de las artes escénicas y de la pedagogía, tengan una nueva mirada al teatro na práctica pedagógica.

PALABRAS CLAVE: Educación. Artes escénicas. Teatro. Alfabetización.

ABSTRACT: The present study aims to discuss the importance of theater and its relation to education in the sense of considering the benefits that this language can provide for classroom pedagogical work, thought as a methodological element in the practice of literacy, emphasizing their contribution to the literacy process for the integral development of the child. This theme is inserted in the current discussion on the specificity of the scenic arts especially in the sense that the theater has as a resource that needs to be seen in a systematic way and recognized as a scientific field with intentionality in the formation of the small child in the process of literacy. The key question implied by the analysis is: What is the relationship between art and education and how theater can be considered as a relevant and intentional subsidy in the teacher's practice in the child's education process in literacy? It is a qualitative research based on the critical dialectical approach that proposes a differentiated methodological possibility of teaching, to dynamize the practice in the classroom, thinking the theater as a differentiated resource in literacy, in the initial years of Fundamental Education. This study seeks to contribute to the professionals of the performing arts and pedagogy, have a new look at theater in the pedagogical praxis.

KEYWORDS: Education. Scenic arts. Theater. Literacy.

\section{Introdução}

O presente estudo objetiva-se discutir a importância do teatro e sua relação com a educação no sentido de considerar os benefícios que esta linguagem pode proporcionar para o trabalho pedagógico na sala de aula, pensado como um elemento metodológico na prática de letrar e alfabetizar, enfatizando sua contribuição ao processo alfabetizador visando o desenvolvimento integral da criança. Propõe ainda pensar a prática teatral como metodologia para a alfabetização e letramento nos anos iniciais do Ensino Fundamental, como uma prática 
artística educativa para a formação das crianças, proporcionando a promoção do desenvolvimento integral nos aspectos: cognitivo, emocional-afetivo, social.

Perceber o jogo teatral como um colaborador na construção e desenvolvimento da personalidade da criança, em seus aspectos cognitivos, afetivos e sociais é extremamente relevante no processo de formação das máximas capacidades humanas especialmente no processo de alfabetização. Assim, pode-se pensar o teatro como um agente mediador, ampliando as potencialidades da criança, a exploração da ludicidade, a criatividade, além de mostrar a contribuição da presença do teatro na vida do sujeito como um aspecto que pode ser concebido de maneira sistemática e intencional na escola.

Ao percorrer o contexto histórico do teatro infantil, compreendendo como essa linguagem foi se produzindo ao longo dos tempos, bem como o espaço que tem conquistado, observa-se que este se tornou uma área de interesse e estudo com destaque em vários campos profissionais, e nesse ensaio a análise focará a escola como esfera privilegiada de socialização dos conhecimentos em que o teatro ganha notoriedade. Dessa maneira, é mister salientar que essa pesquisa pretende ainda desvelar como o teatro pode ser um instrumento metodológico propiciador da aprendizagem e desenvolvimento infantil em sala de aula. E ainda, ao analisar os documentos oficiais que legislam a educação no Brasil observa-se a legitimidade que essa atividade possui com a educação, na conversão de um aliado na árdua tarefa de alfabetizar as crianças.

É relevante destacar que explorar as técnicas teatrais como recurso para a alfabetização e letramento, com a finalidade de desenvolver na criança a habilidade de leitura, escrita e interação social é premissa significativa quando relacionada a educação uma vez que estimula a criatividade, imaginação, dando possibilidade para que elas aprendam por meio do jogo, ludicidade e brincadeira.

Nesse estudo, se buscará analisar primeiramente o contexto histórico do teatro infantil, resgatando o sentido etimológico e origem do termo e suas significações ao longo do tempo; no segundo momento evidenciará o binômio teatro e educação em que se vislumbra uma relação possível. Também se examinará o teatro como recurso no processo de alfabetização e letramento e por fim se refletirá na formação do professor como possibilidade de superação das dificuldades encontradas no contexto da sala de aula. 


\section{Contexto histórico do Teatro Infantil}

Etimologicamente o termo teatro tem origem grega surgido por volta do século IV a.C, o qual significa "lugar para ver", theatron, que caracteriza o conjunto de obras dramáticas para encenações às pessoas, realizadas em cerimônias religiosas. Por outro lado, o termo expressa uma maneira de objetivar a arte cujo intuito é despertar nos sujeitos os mais diversos sentimentos e emoções. Sua história remonta à sociedade primitiva em que existiam formas de rituais por meio da dança, imitações de animais e outras práticas festivas.

No Brasil o teatro emergiu no século XVI por intermédio de composições teatrais escritas pelos jesuítas com cunho religioso a fim de alcançar os índios. Em meados do século XVII e XVIII, haviam os teatros de marionetes e fantoches que se apresentavam ao ar livre, esses eram assistidos por crianças também. No entanto, podemos dizer que apesar do estreito laço que este gênero sempre manteve com o teatro infantil, seus temas e formas de representação estavam mais próximos do público adulto do que do infantil.

Logo depois, em fins do século XVIII e início do XIX, o que se via com frequência no Brasil eram crianças representando para adultos, em companhias infantis formadas por jovens estrelas de 9 a 14 anos que brilhavam nos palcos, cantando, dançando e representando. Tinham fãs que se reuniam em clubes para homenageá-las. Também contavam com um público infantil, mas essa não era propriamente uma questão, pois representavam peças do repertório clássico de teatro.

A história do Teatro no Brasil no início teve um intuito catequético e jesuítico, em que começou com o Padre Anchieta e o Padre Manoel da Nóbrega, eles utilizavam como forma de auxiliar didática e pedagogicamente a catequese. A medida que se observou o teatro causando impacto no comportamento das pessoas a partir das representações, dramatizações nos seus mais variados gêneros, foi-se modificando, auferindo referências Europeias, no entanto é interessante destacar que até meados do século XX não havia produção específica para o público infantil, embora convém ressaltar que essa prática foi se aprimorando de maneira mais acentuada desde seu início desde o século XIX.

Um dos primeiros espetáculos teatrais voltado ao público infantil foi " $O$ casaco encantado”, de Lúcia Benedetti, encenado em 1948. Essa produção é um marco de uma dramaturgia pensada para as crianças. Antes, as crianças iam ao teatro com os adultos assistir espetáculos voltados aos mesmos, além disso as peças infantis eram de cunho moralizante, como por exemplo: “A lebre e a tartaruga", "A cigarra e a formiga", "O leão e o rato". Tendo 
somente seu espaço em escolas, nada profissional. A peça de Benedetti foi a primeira concebida especialmente para o público infantil (MOURA, 2005, p. 5).

Logo depois da estreia de 1948, foram fundadas companhias de teatro infantil formadas por atores, diretores, autores e produtores profissionais. No Rio de Janeiro, Pernambuco de Oliveira e Pedro Veiga fundam o Teatro da Carochinha e, no mesmo ano, Tatiana Belinky e Julio Gouveia fundam "O Teatro Escola de São Paulo (TESP)", e estreiam com Peter Pan a série de espetáculos teatrais para crianças baseados em contos clássicos. Outra escritora que produz textos para o teatro infantil é Maria Clara Machado, além de escrever peças, fundou a escola Tablado em 1951 no Rio de Janeiro. Segundo Lopes apud Moura (2005, p. 4), nos estudos acerca do teatro, a autora evidencia que:

[...] O que caracteriza o fim dos anos 70 e início dos 80 é o equilíbrio. Estamos saindo de um teatro didático para conquistar um teatro de caráter lúdico. Voltam a aparecer os personagens clássicos, adaptados a nova linguagem. Não há mais o teatro de fantasia exacerbada nem o pedagógico despojado. [...] A realidade pode ser mostrada usando fantasia. Até os cientistas usam a imaginação para fazer suas obras. O que o espetáculo não pode é provocar confusão entre realidade e fantasia. Esse consenso é um exemplo da evolução teatral infantil, não só a nível linguístico, mas também no modo do teatro encarar seu público.

Assim, o teatro infantil passou a apresentar um caráter profissional, atraindo as atenções para a qualidade das produções. Em 1995 é criado por profissionais da área do teatro infantil o CBTIJ - Centro Brasileiro de Teatro para a Infância e Juventude. Sem fins lucrativos é uma entidade que visa a união dos profissionais da área e a expansão de um teatro de qualidade com a finalidade de se promover a formação da infância e da juventude brasileira. O CBTIJ é representante no Brasil da ASSITEJ - Associação Internacional de Teatro para a Infância e Juventude, em atividade em mais de 80 países. Em 2001, a ASSITEJ instituiu a data de 20 de março como o Dia Mundial do Teatro para a Infância e Juventude.

Pensando o teatro no âmbito escolar, apesar de ser um elemento pouco estudado no campo acadêmico, é considerada uma ferramenta que auxilia no desenvolvimento humano ampliando a percepção e sensação do universo artístico e cultural elevando qualitativamente a capacidade de apreciação estética, além de possibilitar compreender a realidade social na qual o sujeito está inserido. Assim, é essencial se pensar na relação entre o teatro e a educação no sentido de buscar formas que auxiliem no desenvolvimento da criança. 


\section{Teatro e Educação: uma relação possível}

Em 1971, com a nova LDB 5692/71, o ensino de Arte passa a ser incluído no currículo escolar, não como disciplina escolar e sim como uma atividade educativa, no documento curricular a disciplina possuía divergências quanto à compreensão, Magaldi (1997) apud Bandoch (2012 p. 14) diz que:

[...] Na escola tradicional o Ensino da Arte era visto apenas como as habilidades manuais, os professores trabalhavam com exercícios de modelos para seus alunos, e o ensino da Arte era visto para o domínio técnico. A disciplina de Desenho era dividida em: desenho geométrico, desenho do natural e de desenho pedagógico estando voltado mais para o caráter de qualificação profissional do que para uma experiência em arte. Já as atividades de teatro e dança eram apenas aceitas quando faziam parte das festas escolares nas celebrações de datas comemorativas, cujo objetivo era o da apresentação e as falas eram decoradas.

Observa-se na fala de Magaldi que a visão de arte era restrita a uma pequena área das artes visuais, e o teatro era compreendido como um evento festivo, espontâneo e não como um objeto de ensino e aprendizagem. No ano de 1996 com a implantação da Lei de Diretrizes e Bases da Educação Nacional (LDB) nº 9.394/96, a Arte passa a ser vista como disciplina obrigatória passando a introduzir as quatro linguagens artísticas como: artes visuais, a música, a dança e o teatro. Sobre a proposta geral dos Parâmetros Curriculares Nacionais (PCNs, 1997), a disciplina de Arte tem uma função tão importante quanto os demais domínios dos conhecimentos no processo de ensino e aprendizagem, tendo as suas especificidades. Conforme os documentos que trazem a arte o PCNs avulta que "A educação em arte propicia o desenvolvimento do pensamento artístico, que caracteriza um modo particular de dar sentido às experiências das pessoas: por meio dele, o aluno amplia a sensibilidade, a percepção, a reflexão e a imaginação." (1997, p. 15).

É mister salientar que a arte, especificamente a linguagem teatral, traz para a vivência das crianças muitos benefícios, elas aprendem a improvisar, desenvolver a oralidade, a expressão corporal, o emocional, a sociabilidade, a coletividade, desenvolve habilidades de pesquisa, leitura, autoconfiança, organização do pensamento.

Aproximar o teatro para o contexto da sala de aula, dentro do conteúdo proposto, é algo extremamente difícil de se realizar pois se trata de uma problemática que exige uma análise aprofundada. É imprescindível que se utilize dos meios disponíveis no teatro no trabalho pedagógico no processo de letramento, de forma lúdica, divertida, explorando variadas maneiras de proporcionar o conhecimento, no entanto, sem esquecer o teatro como arte, pois 
essa questão já é uma tarefa que exige uma determinada atenção, nesse sentido, pensando também no teatro como arte, Arcoverde, (2008, p.9) diz:

O teatro precisa ser levado à sala de aula como arte, assumindo o seu papel como obra de arte. Através dele, a criança vai se deparar com uma das mais antigas manifestações culturais, e diante dessa manifestação cultural, aprenderá e verá que o teatro discute sempre as questões existenciais do homem no mundo. É dentro dessa perspectiva que o teatro tem a sua função estética, catártica, questionadora, transformadora, política e social - uma obra de arte enquanto atividade artística que expressa o homem e os seus sentimentos.

Sendo assim, o teatro cumpre duas funções: como obra de arte e como instrumento para a alfabetização, a criação artística feita pela criança, a independência dada a ela nos jogos teatrais, possibilita uma interação com o mundo das palavras, a literatura. Num contexto social aprisionado pelas mídias sociais, aliar uma prática teatral à vivência escolar, pode colaborar nos mais diferentes aspectos, resgatando o lúdico, o brincar associado a alfabetização e a imaginação. Vigotsky (2009, p.101) traz a importância da criação, da imaginação, não importando sua finalidade, mas sim a ação de criar, imaginar.

Compreendendo então que a arte teatral pode se tornar uma ferramenta de ensino, de forma rica e prazerosa, potencializando a ludicidade da criança, ousar-se o teatro agregando-o como recurso de alfabetização e letramento, e provocar a análise de como os métodos fundamentados no teatro podem ser utilizados na educação da criança nesse nível de escolaridade.

\section{Teatro como recurso na alfabetização-letramento}

Os métodos de alfabetização ao longo do tempo passaram por transformações num constante processo de amadurecimento metodológico, e na maneira como se organizam. Soares, (2003), destaca a necessidade de reconhecer e nomear práticas sociais de leitura e de escrita mais avançadas e complexas que as práticas do ler e do escrever, e também do sistema de escrita. Trazendo os termos "Alfabetizar" e "Letrar", em que alfabetização é entendida como a aquisição do sistema convencional de escrita, e letrar é o uso dessa habilidade nas práticas sociais. Soares, (2003, p. 14) diz que:

Não são processos independentes, mas interdependentes, e indissociáveis: a alfabetização desenvolve-se no contexto de e por meio de práticas sociais de leitura e escrita, isto é, através de atividades de letramento, e este, por sua vez, 
só se pode desenvolver no contexto da e por meio da aprendizagem das relações fonema-grafema, isto é, em dependência da alfabetização.

Existem dois percursos possíveis para se alfabetizar, a via lexical e a rota fonológica. A via lexical, consiste em apresentar as letras e depois os sons que elas representam, a fonológica é o caminho inverso, o som das letras e depois a sua forma. A rota fonológica é bastante eficaz, e é a partir dela que vamos pensar o teatro como método.

O teatro pode possibilitar o desenvolvimento de um trabalho focado na voz, na pronuncia dos sons das letras, no qual pode oferecer à criança uma série de atividades de expressão verbal que o leve a identificar a importância da voz e da fala na comunicação humana, em que o professor poderá identificar dificuldades de fala (REVERBEL, 1997), destarte, o professor pode trabalhar dentro dos jogos teatrais, exercícios que contemplem conteúdos como: altura, intensidade, clareza, ritmo e percepção auditiva, o que possibilitara a criança conhecer inteiramente o panorama sonoro da letras.

É interessante evidenciar que o ser humano é um ser que possui necessidade de comunicação, o qual no decorrer dos primeiros anos de vida desenvolve-se na interação que estabelece com o adulto e pela mediação da linguagem. Mediação em termos genéricos é o processo de intervenção de um elemento intermediário numa relação, esta deixa de ser direta e passa a ser mediada por esse elemento (OLIVEIRA apud MARTINS, 2012. p. 12).

A linguagem é uma função psíquica que pode ser pensada também como ferramenta para a objetivação do processo de comunicação, sendo assim, tanto nas crianças quanto nos adultos, exerce função social. Segundo Vigotsky (2008), a fala a princípio, é global e multifuncional, posteriormente, suas funções tornam-se diferenciadas.

Assim como o teatro é considerado uma forma de se expressar, sendo apreciado como uma das figuras de linguagem. O letramento também começa na expressão, na tentativa de comunicação, interação da criança com o mundo. Vigotsky, (2008, p. 34) enfatiza que, "o gesto é o signo visual inicial que contém a futura escrita da criança. Duas esferas unem os gestos e a linguagem escrita: os rabiscos (desenhos) e os jogos de faz de conta". Trazendo também a fala de Reverbel, (1997, p. 21), que diz:

Quando a criança desenha, faz uma escultura ou dramatiza uma situação, transmite com isso uma parte de si mesma: nos mostra como sente, como pensa, como vê. É um enorme prazer expressar os próprios sentimentos e emoções através da arte. Esse tipo de expressão estimula a autoconfiança e proporciona uma base para níveis mais avançados da arte.

A relação da criança com o jogo, a brincadeira, o desenho, propicia que ela mostre sua visão do mundo pela sua ótica, incentivando seu potencial criador de reinventar. A escola deve 
oportunizar o estímulo da criatividade, fornecendo recursos para que está se desenvolva por meio de manifestações artísticas.

Buscando fazer do teatro um recurso pedagógico eficiente, além de diversificar o repertório em sala de aula, pensando o jogo teatral como um método, suas contribuições para a sala de aula. Russeau apud Reverbel (1997, p. 14) aponta que:

[...] A primeira fase da educação da criança deveria ser quase inteiramente baseada em jogos: "ame a infância; estimule seus jogos, seus prazeres, seus encantadores instintos. Considere o homem no homem e a criança na criança. A natureza deseja que as crianças sejam crianças antes de serem homens. Se tentarmos inverter a ordem, produziremos frutos precoces, que não terão nem maturação nem sabor, logo estarão estragados.

Entender a importância do brincar, do estímulo ao jogo para a vivência da criança, suas implicações para as futuras experiências escolares, é fundamental para apropriação de uma nova visão do brincar, em que criança possa criar, experimentar, se divertir, interagir compreendendo que a brincadeira dá vida à criança, educa-a espiritual e fisicamente (VIGOTSKY, 2009).

A inserção dos jogos deve ser gradual, mediante a aceitação das crianças, pois para muitos a expressão corporal e vocal são vistas com olhos tímidos e amedrontados, em vista disso, é necessário ir incorporando com cuidado. Até a criança conseguir exteriorizar seus pensamentos, sensações e sentimentos, é um trabalho que exige do professor muita cautela e atenção, pois qualquer deslize pode traumatizar a criança, levando-a a ter bloqueios, não só em relação ao teatro e sua forma de expressão, mas também em relação ao seu processo de aprendizagem na alfabetização e letramento.

Levar a criança a descobrir a linguagem por meio do teatro, é uma tarefa que não é fácil, e letrar por meio do teatro, para que as crianças possam fazer o uso social da escrita, exige precaução e responsabilidade, por isso o papel do professor é fundamental nessa etapa. Logo, é necessário que o professor possua um embasamento teórico-metodológico que lhe dê condições de desenvolver seu trabalho com segurança, qualidade visando a formação das crianças. Mas pode-se questionar de qual preparação se fala?

\section{A formação do professor das artes}

Para dar início a esta discussão em torno da qualificação do professor é oportuno enfatizar que a formação do professor é essencial para desenvolver qualquer trabalho com a 
criança, no entanto, é indispensável que o professor domine técnicas, neste caso em específico as teatrais, para realizar o trabalho de alfabetização e letramento usando o teatro como recurso metodológico. Conhecendo bem os princípios básicos tanto da alfabetização como do teatro, o professor poderá apresentar um trabalho interessante em sala de aula, conforme a ideia de Reverbel (1997, p. 160):

Ninguém ser arvora em professor de música ou artes plásticas sem ter uma licenciatura plena, de quatro anos no mínimo, mas todo mundo acha que pode ensinar Teatro às crianças porque assistiu a muitos espetáculos, leu peças e acha que tem um certo "jeito" para a coisa.

O que de fato acontece muito, é a má aplicação do que se pensa ser teatro, jogos teatrais, não sabendo utilizar as técnicas, ou até mesmo aproveitando o que as crianças criam, por não ter um conhecimento sistemático do que é o teatro, e como fazer teatro.

É importante revelar que dados retirados do Censo realizado pelo Ministério da Educação-MEC, sobre a situação dos docentes de Arte na educação básica brasileira, em 2013, somente $6 \%$ dos docentes têm formação específica na área de Arte e apenas 3\% são licenciados em alguma graduação em Arte (Artes Visuais, Música, Dança ou Teatro). No Teatro apenas $0,1 \%$ tem licenciatura e em algumas regiões do país $0,0 \%{ }^{4}$. O que são números preocupantes em relação à importância dada a disciplina.

O educador infantil então, precisa se atualizar e buscar aprimorar o seu trabalho, não deixando seu método se tornar ultrapassado, o subsídio do teatro é uma forma de renovar seu conteúdo e de enriquecimento da prática pedagógica. No entanto, conforme Reverbel (1997, p. 24), é preciso ter cautela uma vez que:

A criança aprende atuando, motivo pelo qual é preciso que o professor lhe ofereça oportunidades de atuação. O clima adequado para a criança atuar deve oferecer ampla liberdade e respeito, levando em consideração principalmente o nível de desenvolvimento em que a criança se encontra. Não se deve atribuir notas ou conceitos à sua produção, pois cada aluno cria na medida de suas possibilidades.

A busca constante por conhecimento deve ser uma meta para o profissional da educação que lida com a formação de sujeitos, essa conscientização precisa ser geral, pois ser professor é uma tarefa árdua que exige comprometimento e responsabilidade com sua atividade - o ensino. Assim, a formação e atualização constante com métodos novos e eficazes proporcionam uma melhor qualidade na educação. 


\section{Considerações finais}

Avalia-se que não exista um único caminho eficiente que leve a criança a se apropriar do sistema de alfabetização, pois de acordo com Soares (2003, p. 16):

[...] não há um método para a aprendizagem inicial da língua escrita, há múltiplos métodos, pois, a natureza de cada faceta determina certos procedimentos de ensino, além de as características de cada grupo de crianças, e até de cada criança, exigir formas diferenciadas de ação pedagógica.

Refletindo sobre a ideia acima, observa-se que o teatro é uma possibilidade, que vale a pena ser concebida como uma ação pedagógica, atribuindo-se maior atenção a esta prática de ensino e aprendizagem. As contribuições de uma prática teatral vão para além das técnicas de alfabetização e letramento, propicia um enriquecimento social e pessoal, que trará muitos benefícios para a comunidade escolar.

Diante do exposto, constata-se que o teatro pode ser examinado como uma forma diferenciada de abordagem no ensino, e que infelizmente nem todos têm acesso, pois ainda é considerada uma atividade elitizada, todavia, o ideal seria a oferta do teatro como disciplina extraordinária em todas as escolas públicas.

Isto posto, avaliamos que o caminho da alfabetização e letramento é árduo e se abre em um leque de possibilidades, ainda assim cabe ao professor a liberdade de escolher qual método é adequado às variáveis da situação e do aprendizado das crianças. Nessa perspectiva, o teatro merece ser refletido e analisado como uma ferramenta que pode auxiliar o trabalho do professor em toda a vida escolar do sujeito, garantindo uma pluralidade de vivências na sua educação escolar, mas para isso é necessário que o professor entenda que sua formação precisa ser contínua e sua prática sistematizada e intencional.

\section{REFERÊNCIAS}

ARCOVERDE, Silmara Lídia Moraes. A importância do teatro na formação da criança. In: Anais [...] VIII Congresso Nacional de Educação da PUCPR-EDUCERE, CuritibaParaná/PR. 2008.

BANDOCH, Adriana Rodrigues Vieira. A inserção do teatro nas séries iniciais do ensino fundamental. 2012. 51 f. Trabalho de Conclusão de Curso (Especialização) - Universidade Tecnológica Federal do Paraná, Medianeira, 2012.

BRASIL. Censo do Professor. Disponível em: http://portal.mec.gov.br/plano-nacional-deformacao-de-professores/censo-do-professor. Acesso em: 25 abr. 2019. 
BRASIL. Secretaria de Educação Fundamental. Parâmetros curriculares nacionais: arte / Secretaria de Educação Fundamental. - Brasília: MEC/SEF, 1997.

BRASIL. Lei de Diretrizes e Bases da Educação. Disponível em: http://portal.mec.gov.br. Acesso em: 28 abr. 2019.

BRASIL ESCOLA. A criança e o teatro na escola. Disponível em: www.brasilescola.uol.com.br. Acesso em: 28 abr. 2019.

Centro Brasileiro de Teatro Infanto Juvenil. Disponível em: http://cbtij.org.br/. Acesso em: 28/04/ 2019.

MARTINS, Onilza Borges; MOSER, Alvino. Conceito de mediação em Vygotsky, Leontiev e Wertsch. Revista Intersaberes, v. 7, n. 13, p. 8-28, 2012.

MOURA, Carolina Castanheda. O Teatro infantil na década de 1980- Um olhar para o universo infanto-juvenil. USP, 2005.

REVERBEL, Olga. Um caminho do Teatro na Escola. São Paulo: Editora Scipione, 1997.

SOARES, Magda. Letramento e alfabetização: as muitas facetas. Universidade Federal de Minas Gerais, Centro de alfabetização, Leitura e Escrita. Revista Brasileira de Educação, outubro de 2003.

VIGOTSKI, Lev Semenovitch. Imaginação e criação na infância. São Paulo: Ática, 1930, 2009.

VIGOTSKI, Lev Semenovitch. Pensamento e Linguagem. Trad. Jefferson Luiz Camargo. $4^{\circ}$ ed.- São Paulo: Martins Fontes, 2008.

\section{Como citar este artigo:}

BARROS, Marta Silene Ferreira; PASCHOAL, Jaqueline Delgado; FERREIRA, Ana Letícia; BARROS, Priscila Cordeiro Soares. Arte e Educação: o teatro como recurso metodológico no trabalho pedagógico na alfabetização. Revista Ibero-Americana de Estudos em Educação, Araraquara, v. 14, n. 3, p. 1205-1216, jul./set., 2019. e-ISSN: 1982-5587. DOI: 10.21723/riaee.v14i3.12491

Data de Submissão: 28/01/2019

Revisões requeridas: 26/02/2019

Aceite em: 28/04/2019

Publicado em: 11/05/2019 